April - 2004

\title{
Broadband: A solution for rural e-Learning?
}

\author{
Robin Mason \\ The Open University, UK \\ Frank Rennie \\ University of the Highlands and Islands Millennium Institute \\ Lews Castle College, UK
}

\begin{abstract}
Rural and remote learners are disadvantaged even with online provision due to poor connections. Broadband offers a potential solution. This paper looks at the initial results of a project to install broadband services in the Western Isles of Scotland. It focuses on the educational potential of broadband and the design implications for online courses. It also considers more informal kinds of learning that broadband facilitates in rural areas.
\end{abstract}

Keywords: broadband; rural development; e-learning; online communication; e-learning course design

\section{Introduction}

Broadband technologies offer the potential to overcome many unique challenges and traditional limitations that characterize the rural economy, particularly those associated with distance and access. Citizens of rural and remote areas have similar needs to those of urban areas, but are disadvantaged in a number of ways. For example, low population density means a lower taxation base to support essential services; geographical remoteness means transportation difficulties; distance from markets can be a disincentive to new business growth; finally, remoteness usually means a lack of access to education, training and professional updating. Economic diversification is considered a key survival mechanism for many rural communities, and high-speed network access offers opportunities for tele-work, call-centre operations, and other distance-neutral applications and services.

This paper reports the initial findings of an ongoing broadband study conducted in the Western Isles of Scotland. It focuses specifically on the e-learning aspects of the study, but does so in the light of broader issues of rural sustainability, technology push, growth of connectivity and the changing nature of learning. In particular, three questions will be addressed:

1. What implications does broadband have for the design of e-learning?

2. What is the level of rural readiness for broadband and e-learning?

3. Do local learning centers have a continuing role with the introduction of broadband to the home? 
An important aspect of the study is to build on the outcomes of other rural installations of broadband technology and to highlight lessons from the early adopters internationally: the smart communities in Canada, the electronic villages in the USA, and the municipal networks of Finland.

The paper begins with an examination of a number of interdependent issues related to broadband and e-learning. It then summarizes relevant lessons from our desk research on broadband for rural and remote areas. We then turn to the presentation and analysis of data from the initial survey and focus on the questions and responses concerning e-learning, taken in the broadest sense. Finally the paper examines the ways in which e-learning providers could capitalise on the growing availability of broadband in the design of e-learning opportunities.

\section{Key Issues}

\section{e-Learning and Connectivity}

e-Learning is one of the most significant uses of broadband to be identified in numerous studies (e.g., Sage Research, 2002; Rural Secretariat Report, 2001). The best e-learning courses offer a wide range of benefits for distance learners:

- Flexibility in terms of both time and place of study

- Access to and guidance through Internet resources

- Engagement with a community of fellow learners and tutors

All of these benefits are equally available to both rural and urban students. This apparent equality is undermined, however, if some students who when logging on and accessing the course over low-speed, unreliable networks, browsing webpages, and accessing multimedia materials, take significantly longer and are subject to many technical hitches. Meanwhile, out-migration of young people has been highlighted as a major concern in many rural studies and recommendations from such research inevitably cite the need for providing further opportunities for rural youth.

Young people continue to leave rural communities to seek employment and higher education. New technologies offer potential for creation of new types of employment for young people, opportunities which can help to retain them in their communities, or attract others to locate there. Without the ability to be 'connected' to the global economy, young people will continue to leave rural places. While high-speed access will not guarantee that youth will stay, return, or on the other hand, move to rural communities, it does provide an additional tool and incentive to help attract and retain young people. It is a prerequisite for the young generation to be connected (Rural Secretariat, 2001, p. 5)

Studies also show that in a knowledge-based society, human capital is the main source of competitive advantage (Levis, 2002). Lifelong learning, both formal and informal, is the key to developing appropriate skills and maintaining employability. Increasingly the skills of knowledge workers lie in the domain of "learning how to e-learn," and clearly this requires good connectivity.

The fundamental reason driving the [e-learning] revolution is the need in a knowledge-based economy for vastly more learning opportunities, both formal and informal, than was previously 
required in an industrial society, and the need for a more systematic approach to the sharing of knowledge. Knowledge workers need to process enormous amounts of information and to tap into the knowledge of others and the collective knowledge of their organisations. They also need to acquire large amounts of knowledge and skills throughout their working lives. Classroom training is often an ineffective as well as expensive way of enabling adults to acquire knowledge, however (Levis, 2002, p. 12).

In theory, therefore, it would seem that broadband technology and the provision of e-learning promise a real solution to rural sustainability, both socially and economically.

\section{Technology Push}

Experience of new technology deployment over many years makes clear that it is the social structures and human processes that need to be re-engineered before the transformative potential of the new technology can be fully realized (Daniel, 2002). As changing human processes and evolving social structures are much harder to effect than installing technology, new initiatives typically tend to grind to a halt after the easy part has been accomplished. It is too simplistic, however, to blame "technology push" as the cause of many failures in the take-up of technologybased innovations. This is clear in the case of broadband where the classic dilemma pertains. The technology needs to be in place before people see how they might use it and before services are created to attract users, thus making the technology available is inevitably a technology-led operation.

Educational institutions are notoriously conservative organizations and though e-learning is currently the innovative face of most universities and colleges, designing online courses and events specifically for a broadband market seems to be too speculative a venture for such publicfunded bodies. So the implementation and take up of broadband technology tends to move in fits and starts.

Following roughly a decade of development and experimentation and a recent period of rapid growth, first-generation broadband services, using primarily cable modems and digital subscriber lines, are available in many markets. This progress, however, is offset by recent business failures and uncertainty about the pace of future investment - factors that in part reflect slow growth in subscriptions of broadband services (NRC, 2002, p. 1).

For rural subscribers in particular, broadband provides higher-performance options in connecting to familiar Internet and other online services. Its enhanced capacity and "always on" nature enables new networked activities, which are largely undeveloped. Evaluations of broadband projects (Lynch, 2000; Sage Research, 2002) generally recognise that true exploitation of highspeed connectivity is still in its infancy.

\section{Broadband and Wider Social Changes}

Broadband technology is only one element in a spectrum of inter-related social changes. The explosive growth in connectivity and the changing nature of the content and processes of learning are intimately tied into the demand for broadband.

Mobile phones, online communities, and Web-based developments like blogging, e-games, and eBay, are just a few components of 21st century life in the "connected economy." The scientific 
and economic underpinnings of pervasive computing have been building for decades, and the social side effects are only beginning to erupt. The virtual, social, and physical worlds are colliding, merging, and coordinating (Rheingold, 2002, xviii).

New technologies create new social environments (Baudrillard, 1993), which alter the nature of social interaction and community. We have moved from the Age of Information to the Age of Connectivity. Broadband - until it is superseded by the next technology - has a role to play in this kaleidoscope of social change.

Changes in education, reflecting these wider social changes, are also beginning to appear. Both the content of what is learned as well as the processes of learning are undergoing a transformation. For example:

Learning-to-e-learn skills are necessary for employability in many fields

The ability to find and analyze information and to identify relevant and reliable material amongst large amounts of data, are more important than learning content

Informal learning - from peers, the workplace, and life events - is taking on greater importance, especially where formal courses are not flexible enough, tailored enough, or modular enough for busy employees

Lifelong learners will inevitably be fitting their learning in and around many other demands on their time. A few course providers (usually from the commercial sector) are beginning to offer learning opportunities that are quickly adaptable to different markets, that can be re-sized, and customized or updated, and that can be produced or perhaps assembled in response to changing demands. Most e-learning programmes emphasise a student-centered pedagogy, in keeping with the passing of responsibility for the general 'health' of one's learning onto the learner or employee. So, for example, online activities develop skills in communication, working in teams, finding and evaluating information resources, storing, accessing and handling large amounts of data, working with new technologies, updating and refining existing skills and knowledge. Finally, the field of professional updating is less about acquiring qualifications and more about learning opportunities. In some employment areas, the beginnings of a convergence between working and learning are evident (Levis, 2002). This has profound implications for educational institutions, and e-learning providers need to lead the way in working through the implications of all these changes in their design and presentation of learning.

\section{Case Study}

\section{Project Background}

This project is an initiative of Lews Castle College, UHI, and the Institute of Educational Technology at The Open University. The study is being funded by the Western Isles Enterprise Company, Comhairle nan Eilean Siar, The Western Isles, Skye and Lochalsh LEADER+, and the UHI Millennium Institute. The study focuses on the potential adoption of wireless broadband in the Western Isles of Scotland, and provides a community perspective with local facilitation and training.

The purpose of this project is to provide a clear understanding of the aspirations and potential demand for broadband connectivity among Western Isles communities and businesses. To provide a baseline analysis for subsequent monitoring of the developing community networks, the 
work focuses on three particular communities. Comparison will also be made with international examples of best practice in community network operations in remote and rural areas, particularly in North America and the Nordic countries. Using identified examples of best practice, the project team will seek to provide specific outcomes for education, social, and business engagement with community networks, which in turn will serve as a model for knowledge transfer to broadband installations in other relevant geographical areas.

The delivery of services to the remote and rural areas of Scotland has already utilised both low and high technology solutions to address the difficulties of a low population density, difficult topography, and economies of scale for certain specialised services. Low-tech solutions include local and regional partnerships to share accommodation, equipment, and staff. In some localities this has resulted in a more integrated structure of the planning process for rural development, and the adoption of innovative approaches to service provision through contract agreements, greater community involvement, and closer community-agency planning. High-tech solutions include the establishment of computer-based networks for the delivery of further and higher education to remote sites, use of telemedicine techniques, and the application of Internet-based business transaction facilities for the marketing, sale, and purchasing of commodities which are generally unavailable in most rural locations.

Scotland has had an early engagement with the use of information and communication technology (ICT) in helping to provide services in rural areas, through such initiatives as the Community Teleservice Centre project of the Highlands and Islands Enterprise, and more recently with the spread of Local Learning Centers through the Scottish University for Industry (SUfI) and the UHI Millennium Institute. Early Teleservice Centers in rural areas were based upon the model of the Swedish Telecottage network, and several of these initiatives still function as rural business centers and provide local training and/or development facilitation. There have also been some recent experiments with telemedicine and e-learning in the form of delivery of health and educational services to localities distant from the specialist provider.

The imminent arrival of broadband wireless connections to the Western Isles offers a unique opportunity to utilise online community techniques to encourage greater social and economic development in and between relatively remote and disadvantaged rural communities. The combination of local community involvement and more effective use of technology offer a powerful combination for transforming the range and the quality of services provided within many rural areas.

\section{Broadband Implementation}

Broadband refers to a new generation of high-speed transmission services aimed at residential and small business users. It is a generic term used in relation to a number of technologies for delivering fast data communications services. There is no agreed threshold, however, that marks the boundary between broadband and narrowband. A recent National Research Center study claims that "various groups have struggled to develop appropriate definitions of broadband, and these definitions have changed over time" (NRC, 2002, p. 3).

Communications capacity or speed is only one of the characteristics that define broadband. Another way of distinguishing broadband - at least from dial-up access - is "always-on" connectivity. There are also other parameters such as bandwidth symmetry between upstream and downstream capacity, latency or delay in how long it takes to deliver a packet across the network, and addressability. All these aspects have implications for the types of services that can be 
appropriately deployed over broadband. Video-on-demand and other streaming media applications rely on the availability of downstream bandwidth, while information appliances require always-on service though the bandwidth requirement is low. The total broadband use in a home may be made up of multiple applications being used simultaneously by different family members. This is relevant to e-learning applications, which are unlikely to be the primary reason for initial broadband take-up, but nonetheless will piggyback on a range of other uses of broadband in the home.

The Western Isles “Connected Communities” project will deliver an innovative high performance broadband wireless network access across the five main populated islands of Lewis and Harris, North Uist, Benbecula, South Uist, and Barra. The "Connected Communities" island network will utilise a combination of fibre and leading edge wireless broadband-based stations and multipoint in-community links. This will allow new networks to be demonstrated in community locations, and provide tele-workers and local companies with high-speed connections through wireless antennas. Initially schools, health centers, and council offices will receive a high-speed connection and through this same infrastructure, the rest of the community will gradually have access as the network develops.

\section{The Use of Existing Literature}

One aspect of this research has been to carry out a survey of findings from similar implementations to ascertain best practice and benefit from the mistakes of the earliest adopters. Three elements characterised our literature search for similar studies:

- The use of broadband connectivity

- An isolated rural context

- An e-learning focus

Apart from the UK itself, which also has a number of relevant implementations in rural parts of Wales, Yorkshire, Devon, and the East of England, the USA, Canada, Nordic countries, and Korea were the leading areas of rural broadband roll-out. The most extensively researched programmes were several Canadian and American studies, which provided valuable research reports and longitudinal evaluations of the use of broadband in rural areas (Kavanaugh, 1996a; Kavanaugh, 1999; Smart Communities, 2002; The National Broadband Task Force, 2002; The Rural Secretariat, 2001). The most notable finding from all of the studies was how similar the results, recommendations, and issues were across a wide range of implementations. These can be summarised as follows:

- Development of a community of broadband users requires more time, support, and investment than is usually anticipated - far more than the simple implementation of the technology

- The best community developments are led by the community - specifically those local early adopters and champions - and not by outside enthusiasts or technologists

- E-learning take-up is based on the greater speed, reliability, and "always-on" nature of broadband, rather than its capacity to deliver high-bandwidth material or real-time video applications

- E-learning is a growing market but e-shopping, communications and entertainment are the primary drivers of domestic broadband take-up 
- Informal learning, pursuing leisure interests, peer-to-peer learning in online communities, and accessing information (i.e., about health matters), are as big a component of the elearning market-space as formal, accredited online courses

- The development of online community enhances rather than reduces face-to-face community in rural settings

- Public access sites (e.g., tele-cottages and libraries) demonstrate a growing rather than declining demand in broadband-rich areas

Our Western Isles project has used these findings in a number of ways. Most importantly, we have enlisted the support of six existing local community facilitators to raise awareness of the broadband implementation, to work with existing communities to capitalise on the facilities, and to animate online discussions and other networked activities. Second, we have replicated many of the questions from broadband studies elsewhere in our initial survey, in order to benchmark our study against other rural implementations. Third, we have placed our initial emphasis on commercial and social uses of broadband and encouraged the creation of online community and informal learning opportunities. We are putting in a further research proposal to work with existing educational providers to develop formal courses specifically for the rural broadband market. Finally, we are working with existing staff at local learning and resource centres, collaboratively analysing the results of our survey and conducting interviews with current and potential users of their facilities.

\section{Findings}

\section{The Initial Survey}

In order to obtain baseline statistics on existing online activity with which to compare subsequent broadband uses, we conducted a survey prior to the implementation of the high-speed technology. We used (with permission) some of the questions from a similar survey originally conducted in Grand Rapids, USA, primarily because this implementation is well documented and a longstanding rural broadband study. (Arguably many of the Canadian implementations have more in common with the context of the Highlands and Islands of Scotland, but they are not as far advanced and so do not provide benchmarking data).

The questions aim to establish what kind of connectivity people currently enjoy and how they use the Internet. The survey goes on to ask what kind of uses people might make of connectivity if they had broadband access. Finally, it asks what areas of education and training would be of interest if an "always on" network were available.

\section{Profile of Questionnaire Respondents}

Of the 200 questionnaire respondents, 66 per cent were male and 33 per cent female. This is the same gender distribution as the Grand Rapids initial survey. Questionnaire respondents' age range was from 18 to 70, with the majority between age 30 and 50. Interestingly, over 85 per cent owned a mobile phone, and 90 per cent had a personal computer in their home. Fifty-seven per cent indicated that they had their own website, and 78 per cent considered themselves to be "very" or "fairly" competent users of the computer and the Internet. Forty-five per cent indicated that they had been using the Internet for 4-6 years. 
Clearly the respondents are not representative of the population as a whole. The questionnaire was available on an open website and received publicity through local meetings, newspaper articles, and personal contacts by local facilitators. There were also parallel promotions of the broadband implementation through "road show" presentations in several locations on the islands. Nevertheless, those who have taken the time to fill in the questionnaire reflect a subset of the total island population that is most computer literate, most "connected" and most interested in what broadband has to offer. Surveys carried out in Blacksburg, Virginia in 1996 and 1999 (another relevant rural broadband initiative of long standing) reflect a similar subset of the local population, in that 87 per cent of initial users of the technology were affiliated with the local college (Kavanaugh, 1999).

Respondents were asked whether they ever accessed the Internet from outside their home and workplace. Two categories were provided: public locations such as the library, school or local learning centre and other locations such as friends' homes or cyber-cafes. Figure 1 shows a relatively modest level of access from public locations, but clearly the majority of respondents have made some use of Internet access from machines other than their own. We intend to follow up the survey with personal interviews, and this is one of the questions we will investigate - for what reasons and under what circumstances do people use other locations to access the Internet.

Figure 1. Respondents’ Access to the Internet Outside their Home

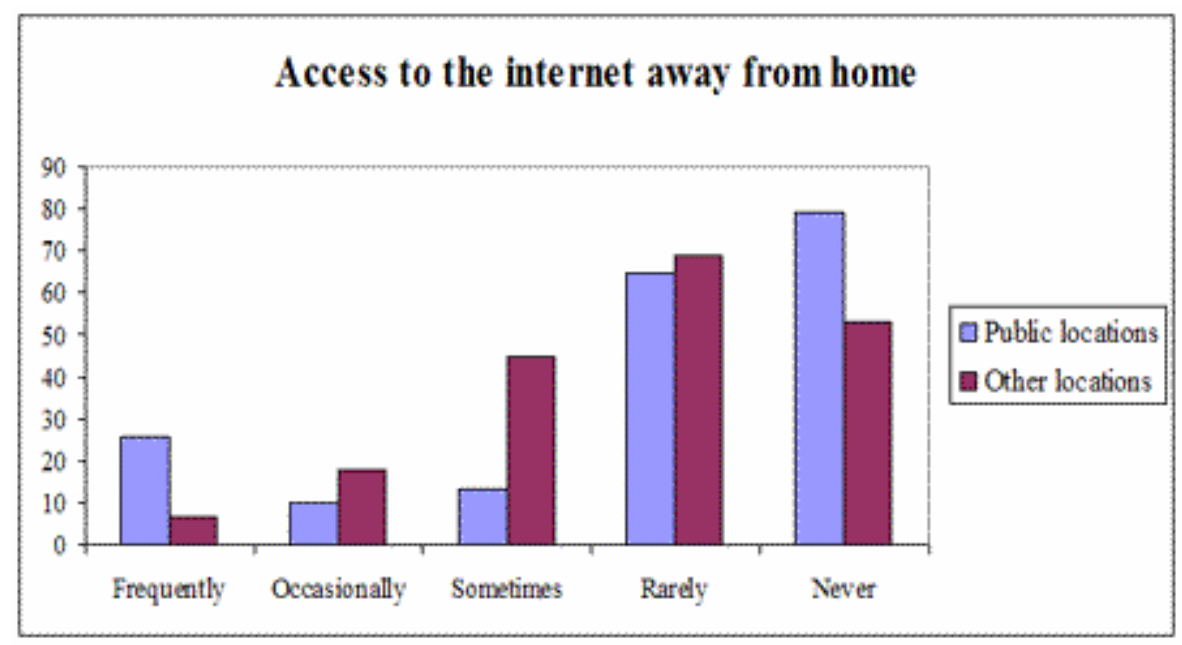

An open-ended question then asked respondents to describe what limitations they personally experience to greater use of the Internet. The overwhelming majority (80 per cent) cited slow speed as the main deterrent. Poor connections and the cost of connecting were listed by a further 15 per cent. The final 5 per cent cited lack of time.

A series of questions then asked respondents to say how their involvement with other people and with local issues had been affected by their use of the Internet. Sixty per cent said their connection to other people had increased considerably, and 55 per cent said their involvement with local organisations had increased. This finding confirms other studies that show that online connectivity complements face-to-face connectivity. 


\section{Current and Anticipated Uses of the Internet}

Using a number of questions from the Grand Rapids survey, we asked people to categorize their current use of the Internet for a range of formal and informal learning opportunities. We asked how frequently they used the Internet to find out about local news and events, and to obtain information from local public agencies. While these show relatively high uses, the more directly educational uses are significantly higher. Nearly 50 per cent said they frequently used the Internet to gain knowledge of various kinds. Three more specific kinds of educational uses were surveyed:

- Developing computer skills

- Obtaining educational materials

- Studying distance education courses

Respondents were then asked to speculate about how much they would use the same range of informative and educational activities when they had access to broadband. The figures below compare their current and anticipated use for the same activities.

While speculating about future uses is not entirely possible, the data nevertheless indicate something about expectations and possibilities. Figure 2 shows that respondents are clearly expecting to use broadband to access local information far more frequently than currently. As subsequent comparisons show (e.g., Figure 6), there is a greater growth in anticipated uses of broadband for local information and community networking thSan for specifically educational uses.

Figure 2. Respondents' Current and Anticipated Use of the Internet to Obtain News and Information

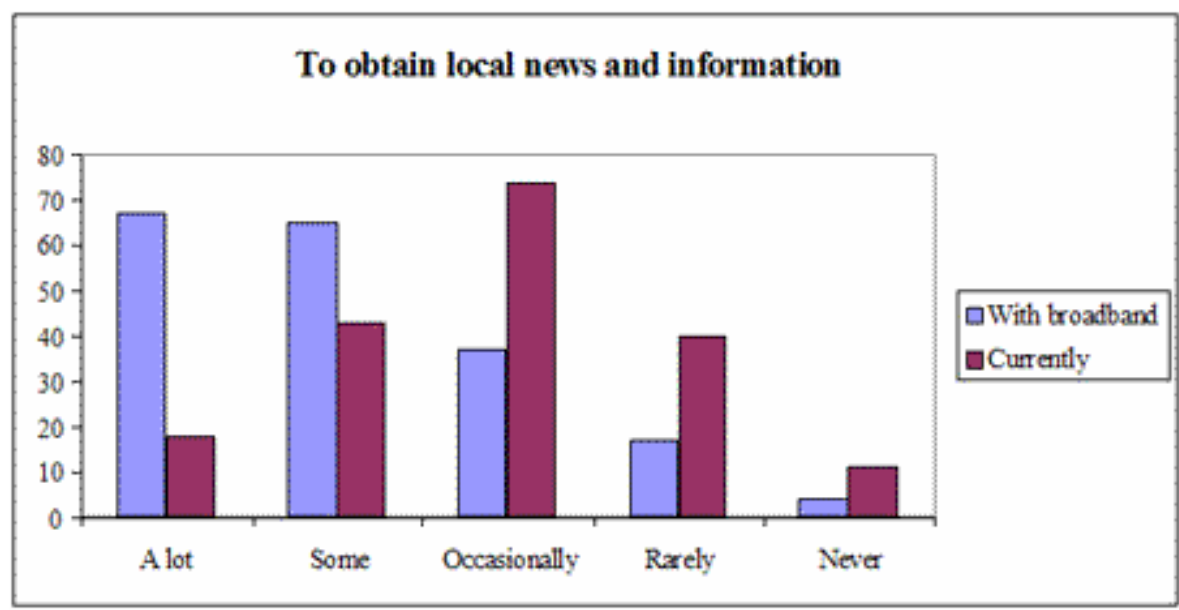

Figure 3 shows a similar rise in anticipated broadband use to access information from public agencies. In particular, we asked respondents to indicate whether they would use broadband to access information about local health provision. Three quarters of them said they would either frequently or sometimes. 
Figure 3. Respondents' Current and Anticipated Use of the Internet to Obtain Information from Public Agencies

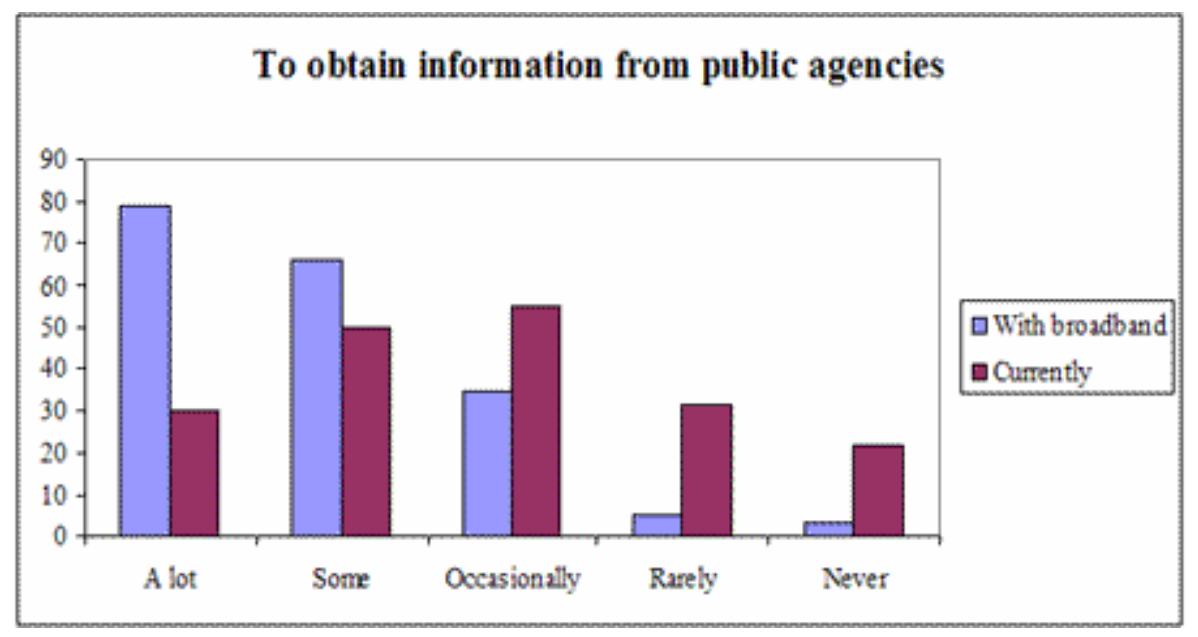

Using the Internet to develop computer skills is already a common activity among respondents, but this too is expected to rise with the availability of broadband as Figure 4 shows.

Figure 4. Respondents' Current and Anticipated Use of the Internet for Developing Computer Skills

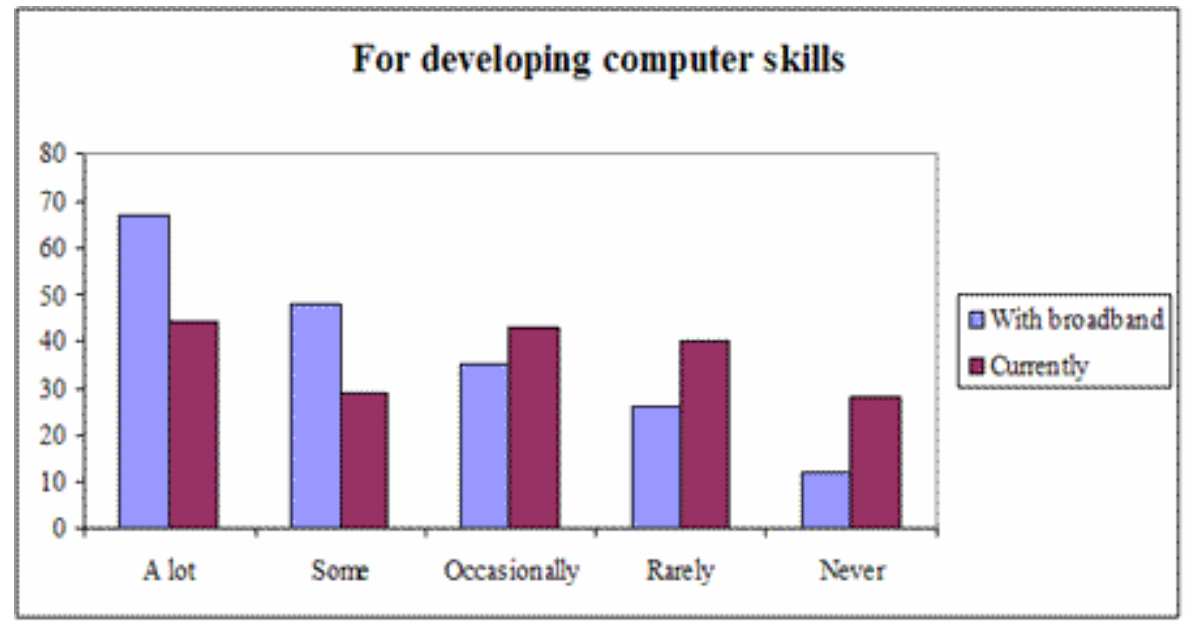

Figures 5 and 6 show that this group of information technology (IT) literate respondents already make relatively high use of the Internet for education, but these are also expected to rise with broadband. Note that both the current and the anticipated uses of the Internet are higher for "obtaining educational materials" than for formal distance education courses. 
Figure 5. Respondents' Current and Anticipated Use of the Internet to Obtain Educational Materials

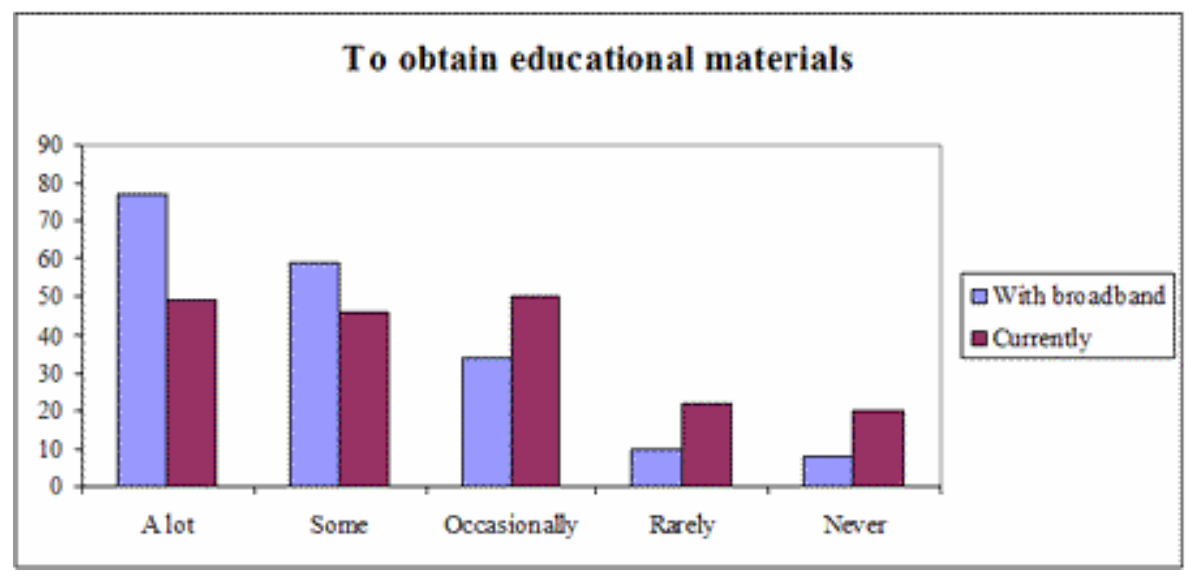

Respondents were also asked to describe their concerns about the introduction of broadband and hence their greater use of the Internet. Issues mentioned were:

- It can be addictive and time wasting

- Virus problems and security issues

- There are questionable websites, especially for young people

Figure 6. Respondents' Current and Anticipated Use of the Internet for Taking Distance Learning Courses

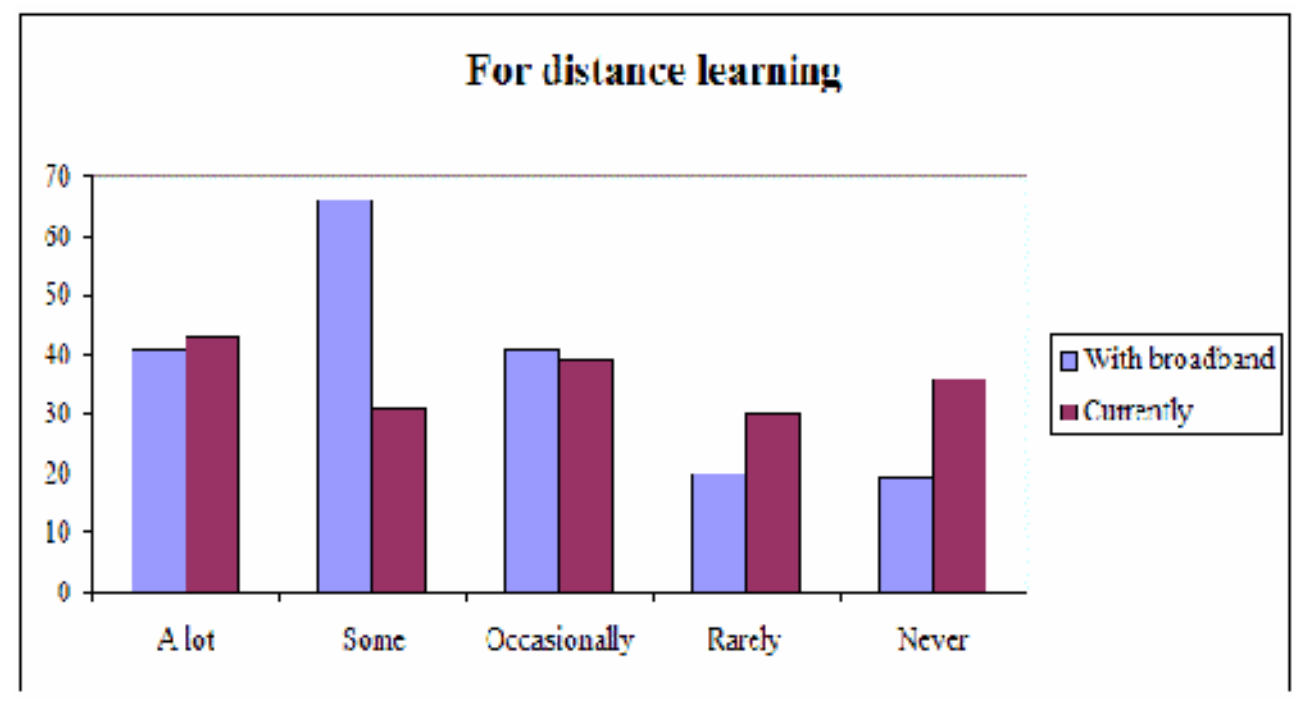

Nevertheless, many respondents said the Internet was largely beneficial and they only saw it positively. Perhaps the most indicative response was: "The Internet is a double edged sword. Buying online is fantastic, but presents challenges to local retailers who need to compete to survive. In the long run, it will have a negative as well as a positive effect on the local economy.” 


\section{Training Requested}

Training in basic Web-design was requested by half of the respondents with only slightly fewer requesting training in using Web-based educational materials. Nearly 40 per cent asked for training in databases and PowerPoint, and 30 per cent in spreadsheet applications. In an openended question about other kinds of training which would be of interest, the most often mentioned requests were for various kinds of advanced training, for example, in Web-design, producing educational Web material, marketing online, and multimedia applications using video and audio. Given the acknowledged IT competence of these respondents, the level of interest in training represents a clear market opportunity for the local college and other training providers to upon which to capitalise.

When asked what services they would like to see provided locally, a wide range of interesting, relevant, and innovative suggestions were made. Figure 7 shows only the most common.

Figure 7. Respondents’ Requests for Desirable Online Local Services

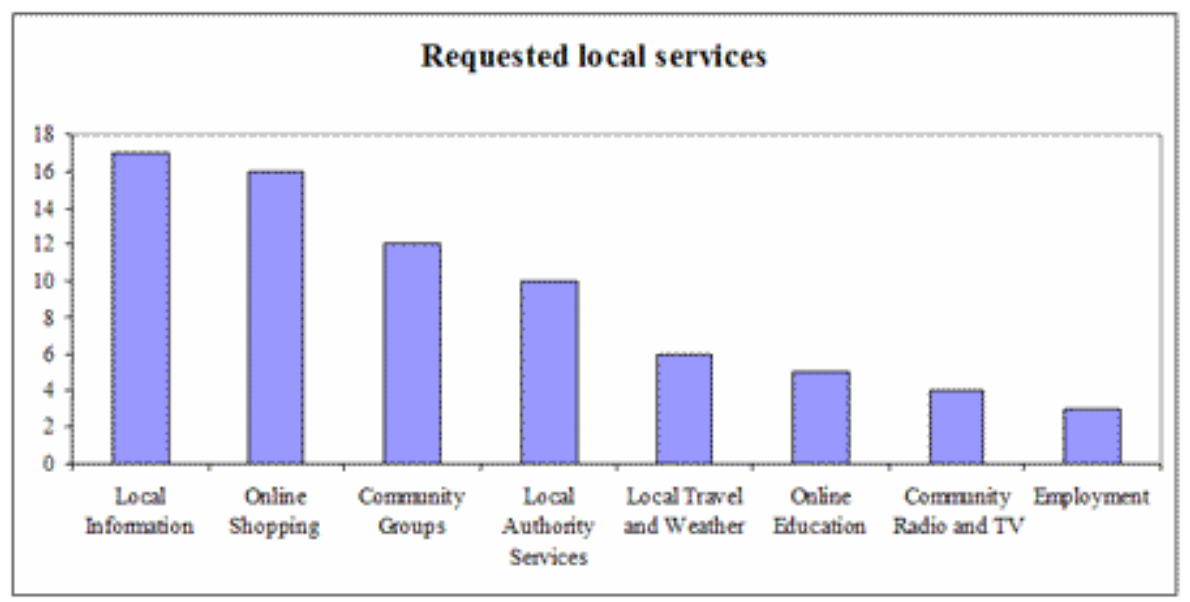

These open-ended responses confirm earlier data about interest in local opportunities for a wide range of activities ranging from shopping to socializing, from community development to information services. Again, it is notable how much stronger the demand is for local information than for formal educational opportunities.

The final open-ended question asked respondents to comment on the opportunities they perceive with the introduction of broadband. Most responses focused on the employment possibilities that could come to the islands:

"Increasing small cottage industry expansion in remote areas - crucial. Better connection with the rest of the world. Tourist opportunities, economic opportunities, educational opportunities.”

"Allow people to work from home and encourage businesses to set up locally."

"A council that is more aware of local problems; international companies working from the islands; better links to the rest of the world; a feeling of being less isolated etc. The only limitation is the imagination of those that use it." 
"Marketing a more positive image of the Western Isles to the world; potential for Gaelic development."

Two comments were more acerbic:

"If broadband is to be introduced to the Western Isles, it should not be on a piecemeal basis, but made available to all areas equally and if phased, should start in the most remote area from Stornoway - i.e., Barra and Vatersay and work northwards from there. 'Pilot projects, which start in one area and never spread beyond, are potentially counterproductive if they serve only to reinforce a perception that some communities are more favored than others. Assuming equal access to the same level of connectivity, then the opportunities are enormous not just in education (for widening and deepening the curricular spread), but also in the business and voluntary sectors. It could really bring the island communities together."

"If it's a tool to facilitate action locally, it is great. If not, then it is just another reason (like TV) for people to stay in their houses behind a VDU [video display unit] rather than getting out in the community and meeting people."

\section{Analysis}

The data present us with a picture of the current and future activities of a small, unrepresentative subset of the population of the Western Isles. Nevertheless, these are no doubt the very people who will be the first adopters of broadband, and the early champions, providers, and users of local information, services, and training.

The survey shows a strong demand for a whole range of local groups, committees and shops to develop an online presence. For this to happen, awareness raising, training, and support will be necessary. Studies in North America and Finland are adamant that nurturing efforts - in the form of training and on-going support - are absolutely essential if the whole initiative is to be successful.

Existing local centres have an obvious role to play in the short to medium term. Raising awareness, using local facilitators, will be the first requirement. Introductory training is probably best handled face-to-face in local centres, while advanced training may be best offered totally online. Evidence from broadband implementations in other countries indicates that local learning centres, even in the medium term, continue to act as vital centers where people come to access a range of resources (e.g., subscription-only material), obtain help and advice, socialise, and try out software before purchasing.

\section{Informal Opportunities for Learning}

The survey also indicates that informal learning will be a large component of the overall use of broadband. The Internet provides two kinds of informal learning opportunities:

Online communities offering advice, socializing, support, and networking

Portals or gateways to information, resources, and articles 
This study shows how important both of these are at a local level, but they need support, maintenance, and promotion. The Blacksburg evaluators noted:

What we DO know is that if computer networking is a medium that can help increase community participation, it will not do this by itself. We, as citizens and community leaders must create the 'structure' and the 'space' - a virtual commons - within which discussion can flourish. We must cultivate group participation by moderating discussion, updating content, archiving conference discussions, organizing information into dynamic, usable, and readily accessible, material full of feedback options (Kavanaugh, 1996b, p. 4).

The community net in Upper Karelia, Finland, attributes its success to the free support and training it provided:

The key implementer was local, the project leaders were local, and the laytrainers had themselves been local unemployed persons; they were highly sensitive to the starting level and needs of the local people. . . Anyone could use the Net and its equipment cost-free at the 32 kiosks that were made available in public spaces, such as libraries, youth centers, homes of unemployed persons, local banks and shops. Training and support was free and easily accessible (Oksa and Turunen, 2000, p. 4).

The Western Isles implementation needs to consider ways of providing support for on-going maintenance of local online networks and information portals. There are also many opportunities for local education providers to offer a broad range of IT training, from the most basic to the most advanced.

\section{Implications of Broadband for Formal e-Learning}

At the simplest level, by providing a faster and more reliable connection to existing provision, broadband will equalise rural and remote learners' access to educational materials and courses. In order to create more attractive and compelling learning environments, course designers could and should therefore be re-thinking the nature of their e-learning courses with the benefits of broadband in mind. From our experience as online course developers, we suggest five such areas for consideration.

\section{Online Activities}

The information and communication aspects of the Internet provide rich opportunities for models of courses that are activity-based and experiential. Activities can be individual or collaborative, and arguably a mix of the two is ideal, as one of the difficulties that even broadband cannot solve is the time constraints many adult learners experience when trying to juggle lifelong learning with professional and family commitments.

Individual activities can make use of the vast resources of the Web to investigate course issues, find and analyse relevant material, prepare reports for a class repository, and comment on fellow students' work. Broadband makes extensive online time affordable and it is less disruptive of family life (i.e., access over dial-up services ties up the one phone line into the household, which can have negative effects). 
Collaborative activities provide the advantages of peer-to-peer learning and a sense of community for isolated learners. Small group activities can involve joint investigations and presentations, and larger teams can produce websites, take part in simulations and role-playing, debates, and structured discussions.

Re-thinking lectures as online activities, provides students with more opportunities to develop self-directed learning skills and resources. Resourced-based learning offers choice and student initiative in making the course their own. Activities can be based around problems (Jonassesn, 2002) or around online seminars and dialogue (Harasim, 2002).

To some extent these activities are already embedded in online courses (Mason, 2000), but broadband access would make them feasible for more learners. Course designers could develop whole courses around the notion of pervasive "always-on" connectivity.

\section{Real-Time Events}

Distance learning and now e-learning has a strong asynchronous bias, mainly because most learners are fitting their studies around other full time commitments. Face-to-face meetings reduce the flexibility of the course, though they would add valuable immediacy, motivation, and presence to the experience of learning. Various forms of real-time connections are possible with broadband that can provide many of these advantages without the flexibility drawbacks typical of face-to-face meetings.

Tutorials and small group meetings can be held over software such as Netmeeting ${ }^{\circledR}$ which provides video, audio and shared screen facilities. Groove ${ }^{\circledR}$ messaging offers near-instant communication as well as shared files, and other software provides buddy systems that allow students to be in close contact with their peers. Activities could be based around these facilities whereby students engage in peer commenting, team projects, and self-help groups.

Webcasting ${ }^{\circledR}$, for example using guest lectures, offers immediacy and the opportunity to engage in discussion with experts and special advisers. The fact the lecture can be stored and accessed after the event provides flexibility as well as immediacy.

Most of these real-time activities are difficult, costly, or actually impossible over dial-up lines. Broadband offers course designers the opportunity to design courses using the optimal mix of synchronous and asynchronous modalities, without concern about disadvantaging remote users.

\section{Hyper-Interactivity}

A whole range of software for simulations, problem-solving and interactive animations used in campus-based learning environments can be implemented for distance learners where broadband is available. Examples include cognitive tools for analysing ideas, dynamic modeling tools for creating representations of mental models, visualization tools for helping to "see" phenomena in different ways, or conversational tools for enabling learners to build collaborative knowledge bases.

The problem or project space must also provide students with the opportunity to manipulate or massage the problem in order to make it more meaningful. Students cannot assume any ownership of the problem unless they know that they can effect the problem situation in some 
meaningful way, so manipulating the phenomena and seeing the results of those manipulations are important (Jonassen, 2002, p. 85 - 86).

Even accessing large databases of articles and interacting with them to find and download appropriate information is made more feasible with broadband than over dial-up lines.

\section{Multimedia}

While true multimedia teaching material is extremely costly to design and produce, there are many ways in which course providers can make use of video and audio clips to add interest and variety to online courses. Used judiciously, both audio and video can provide the kind of immediacy that many distance learners find missing in purely text-based learning material. For example, video and audio clips could be used as annotations to hear or see an expert in the field, to record an interview, to see a process, or to hear the instructor talk through a problem, painting, or procedure. Even pictures, cartoons, drawings, and graphical material add variety to text material, but nonetheless introduce complications in accessing online material for people reliant on dial-up connections. While broadband supports more multimedia than most e-learning course providers can afford to produce, there are many ways in which they could introduce elements of multimedia, which have the desired pedagogical effect without unacceptable cost.

\section{Assessment}

It has been argued (Boud, 2000) that traditional assessment fails to provide opportunities for students to learn the very thing they most need to know: how to assess their own learning. One aim of higher education must surely be to prepare students for an increasingly unpredictable future. There is a need for programmes in which students reach not just immediate course-related objectives, but much wider learning and self-development goals. Existing assessment practices frequently dis-empower learners and put the control and the judgement of learning in the hands of assessors and tutors.

The Web and broadband access to it permit a whole range of online assessments that could begin to address the aim of developing lifelong learners armed with the skills to assess their own learning, give and receive feedback, and make realistic judgements about the quality and value of information. Examples could involve:

Assignments from previous years being made available in a digital repository, which then becomes part of the course resources to be drawn upon by subsequent students

Current assignment being made accessible to students after the submission deadline - with or without grades, and with or without the feedback from the instructor. Students would then be able to benefit from writing assignments for their peers and not just for the instructor

Assigning students the task of commenting on previous students' work

Students are assigned the task of producing websites as assignments, either individually or collaboratively. These can include multimedia elements such as photos and audio clips

\section{e-Learning Providers and Informal Learning}

These five ways of making use of broadband in e-learning are relatively inexpensive but would add richness to the formal online course environment. However, it is evident in this study of the current and anticipated uses of the internet in the Western Isles, as well as in numerous other 
research studies (Levis, 2002), that informal learning opportunities may be more important than formal course provision over broadband networks.

Online course providers might do well to consider the implications of informal learning online and design creative solutions for the broadband market. These might include:

- Short and even shorter learning opportunities

- Online events based around topical issues

- Repositories of professional up-dating material

- Online alumni networks for peer-to-peer exchanges

- E-learning is at the forefront of a revolution in education. Broadband will hasten and support the changes that are already taking place.

\section{Rural e-Learning in Developing Countries}

Though it is beyond the scope of this study, it is nevertheless interesting to consider how applicable broadband is for rural e-learning in developing countries. It is notable that all of the examples drawn upon in this study are from developed countries, whereas the need for educational opportunities in rural areas of developing countries is often even greater. There are two aspects that must be taken into consideration: technology infrastructure and pedagogical readiness.

A recent report about wireless Internet connectivity for developing nations (Press, 2003) indicates that there is some (perhaps over) optimism about the way in which developing nations can cross the digital divide and leapfrog ahead of developed nations using wireless technology. Press is himself doubtful about the reality of such assertions and asks: "Might it be time for some large networking projects rather than demonstrations projects, e-readiness studies, publication of bestpractices databases, etc?” (Press, 2003, p. 8).

Turning to the issues of use, take up, and educational readiness, a number of observations can be made based on the findings in the Western Isles study:

- After funding for the initial infrastructure subsides or is finished, readiness of the population to take up the advantages of broadband is a crucial factor in its sustainability

- Educational providers need to be alert to the training opportunities for both formal and informal learning

- Telecentres offer an interim solution between classroom-based learning and home-based e-learning

- E-learning needs to build on a wide variety of other uses of broadband, such as entertainment, entrepreneurial activities, community networking, and access to public services

These requirements are less likely to be available in developing countries. However, the motivation and determination of many learners in rural, disadvantaged areas often overcome what would be considered insurmountable hurdles even in a developed country. A report (Diamond, 2003) on the take up of Massachusetts Institute to Technology (MIT) open courseware is evidence of this phenomenon. Diamond documents students and institutions using MIT courses in Nepal, Vietnam, Pakistan, and the Mauritius. 


\section{Conclusions}

This paper has examined the learning implications of a larger study of broadband implementation in the Western Isles of Scotland. It has done so in light of similar studies conducted elsewhere and has tried to build on their results. e-Learning has been considered in the broadest possible way to include a range of informal learning opportunities ranging from information portals to community networking, as well as the obvious formal education and training courses.

Although our survey attracted responses from the most IT literate people residing on these Scottish Islands, it is clear that there is at least a small nucleus of people that is ready for broadband and are aware of its educational, economic, and social potential to sustain this remote community. The local centers, which already act as community learning venues as well as the facilitators who run them, have a continuing role to play, though adequate funding needs to underpin their use in the broadband initiative. In order to prevent broadband being viewed as another technology-led project, a range of services must be developed in parallel with the technology implementation. e-Learning opportunities, both formal and informal, are a key part of this "solution" for the Western Isles.

\section{References}

Baudrillard, J. (1993). Symbolic Exchange and Death. Sage Publications: London

Boud, D. (2000). Developing Student Autonomy in Learning (2nd Edition). Kogan Page: London

Daniel, J. (2002). Preface to Distance Education and Distributed Learning. In C. Vrasidas and G. Glass (Eds.) Current Perspectives on Applied Information Technologies: Online professional development for teachers. Greenwich, CT.: Information Age Publishing.

Diamond, D. (2003). MIT Everyware. Wired 11(9). Retrieved September 27, 2003 from: http://www.wired.com/wired/archive/11.09/mit_pr.html

Harasim, L. (2002). What Makes Online Learning Communities Successful? The role of collaborative learning in social and intellectual development. In: Distance Education and Distributed Learning. In C. Vrasidas and G. Glass, (Eds.) Current Perspectives on Applied Information Technologies: Online professional development for teachers. Greenwich, CT: Information Age Publishing.

Jonassen, D. (2002). Learning to Solve Problems Online: Distance education and distributed learning In: Distance Education and Distributed Learning. In C. Vrasidas and G. Glass, (Eds.) Current Perspectives on Applied Information Technologies: Online professional development for teachers. Greenwich, CT: Information Age Publishing.

Kavanaugh, A. (1996a). Highlights of User Surveys 1994-1996. Retrieved December 12, 2003 from: http://www.bev.net/project/research

Kavanaugh, A. (1996b). The Use of the Internet for Civic Engagement: A view from Blacksburg, Virginia. Luncheon Address to the Virginia Municipal League. Retrieved December 20, 2002 from: http://www.bev.net/project/research 
Kavanaugh, A. (1999). Education via Wireless Internet. Roundtable on Tele-Education. UNISPACE III. Retrieved December 20, 2002 from: http://www.bev.net

Levis, K. (2002). The Business of (e)Learning. A revolution in training and education markets. Screendigest: London.

Lynch, C. (2000). Why Broadband Really Matters: Applications and architectural challenges, Educause Quarterly, 4.

Mason, R. (2000). IET's Masters in Open and Distance Education. What have we learned? Retrieved December 20, 2002 from: http://iet.open.ac.uk/pp/r.d.mason/downloads/maeval.pdf

Oksa, J., and Turunen, J. (2000). Local Community Net. Evaluation study of the Learning Upper Karelia Project. Retrieved September 12, 2002 from: http://www.joensuu.fi/ktl/projsoc/infosoc/upperka2.htm

Press, L. (2003). Wireless Internet Connectivity for Developing Nations, First Monday, 8(9). Retrieved January 23, 2004 from: http://firstmonday.org/issues/issue8_9/press/index.html

Rheingold, H. (2002). Smart Mobs. The Next Social Revolution. Cambridge, MA.: Perseus Publishing.

National Research Council (2002). Broadband. Bringing Home the Bits. Washington, DC.:National Academy Press.

Sage Research (2002). Customers at the Gate: Mounting Demand for Broadband-enabled Services. Natick, MA. Retrieved January 23, 2004 from: http://www.sageresearch.com

The New National Dream: Networking the Nation for Broadband Access (2002). Report of the National Broadband Task Force. Retrieved June 12, 2003 from: http://broadband.gc.ca/Broadband-document/table content e.asp

The Rural Secretariat, Agriculture and Agri-Food Canada (2001). Rural and Remote Broadband Access. Background report to the National Broadband Task Force. Retrieved May 12, 2002 from: http://broadband.gc.ca/english/resources/ruralsec_report.html
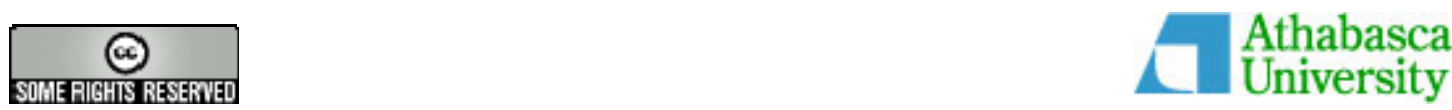